\title{
Pectinase-treated Panax ginseng protects heat stress-induced testicular damage in rats
}

\author{
Min Kyoung Kim 1,5,*, Kyu-Min Cha ${ }^{2}$ *, Seock-Yeon Hwang ${ }^{3}$, Un-Kyu Park ${ }^{3}$, Seok Kyo Seo ${ }^{1,5}$, \\ Sang-Ho Lee ${ }^{2}$, Min-Sik Jeong ${ }^{2}$, SiHyun $\mathrm{Cho}^{4,5}$, Spandana Rajendra Kopalli² and Si-Kwan Kim² \\ ${ }^{1}$ Department of Obstetrics and Gynecology, Severance Hospital, Yonsei University College of Medicine, Seoul, \\ Republic of Korea, ${ }^{2}$ Department of Biomedical Chemistry, College of Biomedical \& Health Science, Konkuk \\ University, Chungju, Republic of Korea, ${ }^{3}$ Department of Biomedical Laboratory Science, College of Health and \\ Medical Science, Daejeon University, Daejeon, Republic of Korea, ${ }^{4}$ Department of Obstetrics and Gynecology, \\ Gangnam Severance Hospital, Yonsei University College of Medicine, Seoul, Republic of Korea and ${ }^{5}$ Institute of \\ Women's Life Medical Science, Yonsei University College of Medicine, Seoul, Republic of Korea
}

Correspondence should be addressed to S-K Kim; Email: skkim@kku.ac.kr

*(M K Kim and K-M Cha contributed equally to this work)

\begin{abstract}
Testicular hyperthermia is well studied to cause impaired spermatogenesis. In the present study, the protective effect of enzymatically modified (pectinase-treated) Panax ginseng (GINST) against intermittent sub-chronic heat stress-induced testicular damage in rats was investigated. Male Sprague-Dawley rats were divided into four groups: normal control (NC), heat-stressed control (HC), heat-stressed plus GINST-100 mg/kg/day (HG100) and heat-stressed plus GINST-200 mg/kg/day (HG200) treatment groups. GINST $(100$ and $200 \mathrm{mg} / \mathrm{kg} /$ day) was mixed separately with a regular pellet diet and was administered orally for 8 weeks starting from 1 week before heat exposure. Parameters such as organ weight, blood chemistry, sperm kinetic values, expression of antioxidant enzymes, spermatogenesis molecules and sex hormone receptors levels were measured. Data revealed that kidney and epididymis weight were significantly $(P<\mathbf{0 . 0 5})$ decreased with heat stress and recovered by GINST treatment. Further, the altered levels of blood chemistry panels and sperm kinetic values in heat stress-induced rats were attenuated when GINST was administered $(P<0.05)$. Furthermore, the expression levels of antioxidant-related enzymes (GSTM5 and GPX4), spermatogenesis-related proteins (CREB1 and INHA) and sex hormone receptors (androgen receptor, luteinizing hormone receptor and follicle-stimulating hormone receptor) were reduced by heat stress; however, GINST treatment effectively ameliorated these changes. In conclusion, GINST was effective in reducing heat-induced damage in various male fertility factors in vivo and has considerable potential to be developed as a useful supplement in improving male fertility.

Reproduction (2017) 153 737-747
\end{abstract}

\section{Introduction}

Global societies consist of older couples getting married unlike that in previous generations. Conceiving at an older age became difficult, and in addition, various factors such as unhealthy lifestyles, substance abuse, environmental pollution, increase in chronic diseases and cancer prevalence have all contributed to an increase in infertility (Eisenberg et al. 2016, Gabrielsen \& Tanrikut 2016, Yao \& Mills 2016). Consequently, infertility has become a major issue, and many couples seek professional help from clinicians. Among the infertility factors, the male factor solely consists of $20 \%$ of the total cause and may contribute up to $40 \%$ of the infertility cases (Berek 2012). Although there are assisted reproductive techniques, they are costly and may require considerable time and effort. Further, there are still many regions where this advanced technology or clinicians are not available. Many male patients hope to improve their fertility without having to undergo certain procedures or surgeries, and several studies strongly recommend medications or food supplements to improve sperm quality (Bardaweel 2014, Kopalli et al. 2015, 2016, Eslamian et al. 2016, Gabrielsen \& Tanrikut 2016, Park et al. 2016, Yao \& Mills 2016).

Spermatozoa are produced by spermatogenesis and sperm maturation that occur in the testis and epididymis. During these processes, it is important that these organs are protected from any factors that may cause damage to the testis/epididymis-related genes. A Chinese study revealed several genes associated with teratospermia that were also potentially associated with sperm quality (Liu et al. 2016). This emphasized that normal expression 
of these testis/epididymis-specific genes is also important for sperm function. Among the factors that may disrupt these processes, heat stress is common. Heat increases oxidative stress, affects mitochondria and results in DNA damage and eventually undergoes spermatozoal apoptosis (Rao et al. 2015, 2016, Hamilton et al. 2016). Heat stress should be avoided, but there are circumstances where heat is inevitable, and therefore, the sperm should be protected by other methods.

Panax ginseng is a well-known herb, which has been used for various health-related purposes since the ancient days throughout Asia, particularly in Korea, China and Japan. Especially, Korean red ginseng (KRG) contains various active constituents, minerals and nutrients, which proved to be helpful to the human body (Ha \& Ryu 2005, Kim et al. 2006). KRG is also known to relieve fatigue, boost energy and function as an immunomodulatory agent. Many clinical studies revealed its effect in improving several diseases including hypertension, diabetes, Alzheimer's disease, acquired immune deficiency syndrome, cancer and sexual dysfunction (Vogler et al. 1999, Hwang et al. 2004, Du et al. 2011, Ramesh et al. 2012, Yayeh et al. 2012, Won et al. 2014, Kopalli et al. 2015, 2016). Recent reports described pectinase-treated extracts of $P$. ginseng (GINST), which contain several ginsenosides with antioxidant effects (Kopalli et al. 2015, 2016, Lee et al. 2016). Additionally, in a previous clinical study, KRG improved sperm parameters, such as sperm concentrations, motility, morphology and viability, but the mechanisms were not clarified (Park et al. 2016). The present study aimed to reveal the effect of GINST on the changes in gene expression, protein expression and sex hormone receptors related to male spermatogenesis in vivo under heat stress condition.

\section{Materials and methods}

\section{GINST preparation and high-performance liquid chromatography analysis}

GINST used in this study was produced from an extract of $P$. ginseng treated with pectinase as described previously (Huo et al. 2008). Briefly, dried ginseng (1 kg) was extracted with $5 \mathrm{~L}$ of $50 \%$ aqueous liquor at $85^{\circ} \mathrm{C}$ and was concentrated in vacuo to obtain a dark brown, viscous solution. The extract was subsequently dissolved in water containing $2.4 \%$ pectinase (Sigma-Aldrich) and was incubated at $55^{\circ} \mathrm{C}$ for $24 \mathrm{~h}$. The GINST extract was subsequently concentrated in vacuo, and the ginsenosides in the extract were analyzed using highperformance liquid chromatography as described previously (Won et al. 2014).

\section{Experimental animals}

Forty male Sprague-Dawley rats (4 weeks old, 60-70g) were purchased from Samtako Bio Korea, Inc. (Osan, Korea) and were acclimated to the animal facility for 2 weeks prior to the experiment. They were provided with a standard pellet diet and were kept at a constant temperature $\left(23 \pm 2^{\circ} \mathrm{C}\right)$ and relative humidity $(55 \pm 5 \%)$ on a $12-/ 12-\mathrm{h}$ light/darkness cycle with access to food and water ad libitum. The rats were maintained in the Regional Innovation Center Experimental Animal Facility, Konkuk University, Korea, in accordance with the Institutional Animal Care and Use Committee Guidelines. The study was approved by the Animal Ethics Committee (Permission No: KU12052) in compliance with Article 14 of the Korean Experimental Animal Protection Law.

\section{Experimental design}

Rats were divided into four groups: normal control (NC), heat-stressed control (HC), heat-stressed plus GINST-100 mg/ kg/day (HG100) and heat-stressed plus GINST-200 mg/kg/day (HG200) treatment groups. Each GINST dose (100 and $200 \mathrm{mg} /$ $\mathrm{kg}$ /day) was mixed separately with a regular pellet diet and was administered orally for 8 weeks starting from 1 week before heat exposure. The GINST dose (100 and $200 \mathrm{mg} / \mathrm{kg}$ b.w./day) was based on our previously reported study (Won et al. 2014). The GINST dose was adjusted every 2 weeks by considering the body weight increment and the daily dietary intake. Rats in the $\mathrm{NC}$ group were maintained at $23^{\circ} \mathrm{C}$, whereas rats in $\mathrm{HC}$, HG100 and HG200 groups were exposed intermittently to high temperatures subchronically: $32 \pm 2{ }^{\circ} \mathrm{C}, 2 \mathrm{~h} /$ day/7 week. In week 9, all animals were fasted for $24 \mathrm{~h}$ with access to water ad libitum and were killed under general anesthesia with carbon dioxide. The testes were excised, washed in ice-cold saline solution and adhering fat and connective tissues were removed. A $10 \%$ testicular tissue homogenate was prepared in Tris-hydrochloride buffer $(0.1 \mathrm{M}, \mathrm{pH} 7.4)$ and centrifuged ( $2500 \mathrm{~g}$ for $10 \mathrm{~min}$ at $4^{\circ} \mathrm{C}$ ) to pellet the cell debris. The clear supernatant was used for the subsequent assays.

\section{Measurement of blood biochemical parameters}

To measure biochemical parameters, blood was taken from the abdominal vein and collected in SST gel and clot activator tubes (Becton and Dickinson, Franklin Lakes, New Jersey, USA). Serum was separated by centrifugation at $1500 \mathrm{~g}$ for $10 \mathrm{~min}$ at room temperature $\left(25 \pm 2^{\circ} \mathrm{C}\right)$. Serum biochemical parameters such as serum glutamic oxaloacetic transaminase (GOT), glutamic pyruvic transaminase (GPT), albumin concentration (ALB), serum total cholesterol (T-CHO), low-density lipoprotein cholesterol (LDL-C), triglyceride (TG) and glucose (GLU) were analyzed using their respective commercially available kits (Diagnostic Product Corporation, Los Angeles, USA).

\section{Measurement of sperm kinematic values}

Sperm samples were extracted from the left caudal epididymis using scissors; one drop of caudal fluid was immediately placed in a culture dish containing $5 \mathrm{~mL}$ of Hanks' balanced salt solution (Sigma-Aldrich), pre-warmed to $37^{\circ} \mathrm{C}$ and supplemented with $10 \mathrm{mg} / \mathrm{mL}$ BSA (bovine serum albumin). After incubation for $5 \mathrm{~min}$ at $37^{\circ} \mathrm{C}$, an aliquot of the suspension was collected with a micropipette and diluted to contain $40 \pm 10$ sperm under the defined microscopic field 
( $\times 100$ magnification); $10 \mu \mathrm{L}$ of the suspension was then added to a 2X-CEL slide (depth: $80 \mu \mathrm{m}$, thickness: $0.15 \mathrm{~mm}$, Hamilton Thorne Res., Massachusetts, USA) that had been pre-warmed in a $\mathrm{CO}_{2}$ incubator (Sanyo Electric Co., Osaka, Japan) at $37^{\circ} \mathrm{C}$. Sperm motility was recorded using a computerassisted sperm analyzer (CASA, Hamilton Thorne Res.) with a $\times 4$ objective lens and a charge-coupled device (CCD) camera. At least 200 sperm in each sample were monitored for motility pattern analysis.

\section{$R N A$ isolation and real-time reverse transcription polymerase chain reaction (RT-PCR)}

For the in vivo analysis, total RNA was extracted from the testicular tissue using the RNA-Bee reagent according to the manufacturer's instructions, and the RNA $(1 \mu \mathrm{g})$ was reversetranscribed following the procedures as described previously (Won et al. 2014). The primers used were listed in Table 1. The PCR was performed for 30 cycles at $95^{\circ} \mathrm{C}$ for $40 \mathrm{~s}, 56^{\circ} \mathrm{C}$ for $40 \mathrm{~s}$ and $72^{\circ} \mathrm{C}$ for $40 \mathrm{~s}$. After amplification, the PCR products were separated using electrophoresis on a $2.0 \%$ agarose gel containing ethidium bromide, and the bands were visualized with ultraviolet fluorescence. The band intensity was analyzed using the ImageJ software package (version 1.41o; National Institutes of Health, NIH). The background was subtracted, and the signal of each target band was normalized to that of the GAPDH band.

\section{Western blot analysis}

Equal amounts of testis protein from each sample were separated with $10 \%$ sodium dodecyl sulfate polyacrylamide gel electrophoresis (SDS/PAGE) and were transferred to a polyvinylidene fluoride membrane (Millipore). Each membrane was incubated for $1 \mathrm{~h}$ in Tris-buffered saline containing $0.1 \%$
Tween 20 and 5\% skimmed milk to block nonspecific antibody binding. The membranes were subsequently incubated with specific primary antibodies (1:1000 dilution; Santa Cruz Biotech). Beta-actin was used as an internal control. Each protein was detected using horseradish peroxidase-conjugated secondary antibodies and a chemiluminescence detection system (GE Healthcare Life Sciences). The relative levels of target proteins to actin were determined by densitometric analysis using ImageJ software. The background was subtracted, and the signal of each target band was normalized to that of the actin band.

\section{Quantitative analysis of ginsenosides by HPLC}

Aqueous 20\% GINST (50 mL) was subjected to butanol $(\mathrm{BuOH}$, $30 \mathrm{~mL}$ ) partition chromatography, three times to obtain a crude saponin (CS) fraction. The CS fraction in $\mathrm{BuOH}$ was pooled and dried in vacuo, dissolved in HPLC grade $\mathrm{MeOH}$, filtered through Millipore filter $(0.45 \mu \mathrm{M}$, Sigma) and introduced to HPLC. The ginsenoside contents in CS were analyzed using high-performance liquid chromatography (HPLC, Agilent) with a diode array detector and C18 column $(4.6 \times 250 \mathrm{~mm}, 5 \mu \mathrm{m}$, Supelco, St Louis, MO, USA), at room temperature $\left(25 \pm 2^{\circ} \mathrm{C}\right)$. The binary gradient elution system consisted of water (solvent A) and acetonitrile (solvent B). The separation was achieved using the following gradient program: $0-10 \min (20 \% \mathrm{~B})$, $40 \min (32 \%$ B), $48 \mathrm{~min}(42 \% \mathrm{~B}), 60 \mathrm{~min}(45 \% \mathrm{~B}), 78 \mathrm{~min}(75 \%$ B) and $80 \mathrm{~min}(100 \% \mathrm{~B})$. The column was kept at constant room temperature and a flow rate of $1.6 \mathrm{~mL} / \mathrm{min}$.

\section{Statistical analysis}

The data are expressed as the mean \pm S.E.M. The data were statistically analyzed using the Student's t-test for comparisons between two groups and analysis of variance (ANOVA) for

Table 1 Nucleotide sequence of primers employed in this study.

\begin{tabular}{|c|c|c|c|}
\hline & Parameter & Direction & Sequence \\
\hline \multirow[t]{6}{*}{ Antioxidant } & \multirow[t]{2}{*}{ GPX4 } & Forward & 5'-GCA AAA CCG ACG TAA ACT ACA CT-3' \\
\hline & & Reverse & 5'-CGT TCT TAT CAA TGA GAA ACT TGG T-3' \\
\hline & \multirow[t]{2}{*}{ GSTM5 } & Forward & 5'-TAT GCT CCT GGA GTT TAC TGA TAC C-3' \\
\hline & & Reverse & 5'-AGA CGT CAT AAG TGA GAA AAT CCA C-3' \\
\hline & \multirow[t]{2}{*}{ PRX4 } & Forward & 5'-CTG ACT GAC TAT CGT GGG AAA TAC T-3' \\
\hline & & Reverse & 5'-GAT CTG GGA TTA TTG TTT CAC TAC C-3' \\
\hline \multirow[t]{6}{*}{ Spermatogenesis-related molecules } & \multirow[t]{2}{*}{ Nectin-2 } & Forward & 5'-AGT GAC CTG GCT CAG AGT CA-3' \\
\hline & & Reverse & 5'-TAG GTA CCA GTT GTC ATC AT-3' \\
\hline & \multirow[t]{2}{*}{ CREB1 } & Forward & 5'-ACT GGC TGC TTT GTG TTC AG-3' \\
\hline & & Reverse & 5'-TAC TAG CTT GGG GAG GGG TG-3' \\
\hline & \multirow[t]{2}{*}{ INHA } & Forward & 5'-AGG AAG GCC TCT TCA CTT ATG TAT T-3' \\
\hline & & Reverse & 5'-CTC TTG GAA GGA GAT ATT GAG AGC-3' \\
\hline \multirow[t]{6}{*}{ Sex hormone receptors } & \multirow[t]{2}{*}{$\mathrm{AR}$} & Forward & 5'-CTG GAC TAC CTG GAT CTC TA-3' \\
\hline & & Reverse & 5'-CCT GGG CTG TAGTTT TAT TG-3' \\
\hline & \multirow[t]{2}{*}{ LHR } & Forward & 5'-CTA TCT ССС TGT CAA AGT AA-3' \\
\hline & & Reverse & 5'-TTT GTA CTT CTT CAA ATC CA-3' \\
\hline & \multirow[t]{2}{*}{ FSHR } & Forward & 5'-GGA CTG AGT TTT GAA AGT GT-3' \\
\hline & & Reverse & 5'-TTC CAT AAC TGG GTT CAT CA-3' \\
\hline \multirow[t]{2}{*}{ GAPDH } & & Forward & 5'-AAC TTT GGC ATT GTG GAA GGG C-3' \\
\hline & & Reverse & 5'-ACA CATTGG GGG TAG GAA CAC G-3' \\
\hline
\end{tabular}

$A R$, androgen receptor; CREB1, cyclic-AMP responsive element binding protein 1; FSHR, follicle-stimulating hormone receptor; GPX4, glutathione peroxidase 4; GSTM5, glutathione S-transferase MU 5; LHR, luteinizing hormone receptor; PRX4, peroxiredoxin 4. 


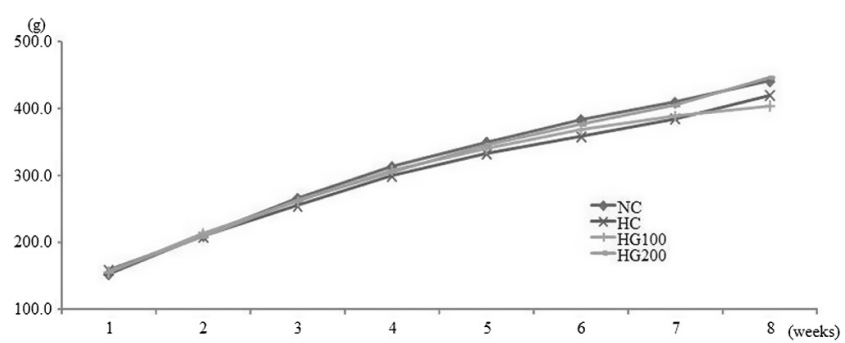

Figure 1 Effect of GINST on body weight increment in heat-stressed male rats. Each point represents the mean $(n=10)$. NC, normal control; HC, heat-stressed control; HG100, HC plus GINST 100 mg/kg b.w./day; HG200, HC plus GINST 200 mg/kg b.w./day.

multiple comparisons, using GraphPad Prism, version 4.0 (Graph Pad Software) and ANOVA followed by Duncan's t-test using the SAS, ver. 9.1 software (SAS Inc., Cary, NC, USA) wherever applicable. A value of $P<0.05$ was considered as statistically significant.

\section{Results}

\section{Effects on body and organ weight changes}

During the test period, all four different rat groups consistently gained body weight (Fig. 1), with no statistically significant differences. The effect of GINST on organ weight in heat-stressed rats is shown in Table 2. Particularly, kidney weight decreased significantly with heat stress $(P<0.05)$, but HG200 group significantly increased the kidney weight to near normal levels $(P<0.05)$ when compared with HC group. Epididymis weight was also significantly decreased by heat stress $(P<0.05)$, but with GINST treatment, the weight of epididymis significantly increased when compared with HC100- and HG200-treated group $(P<0.05)$.

\section{Effects on blood chemistry panel}

The GOT level was significantly elevated with heat stress $(P<0.05)$, but in the HG200 group (Table 3$)$, the level significantly decreased $(P<0.05)$. Further, the $\mathrm{HC}$ group showed a significant $(P<0.05)$ decrease in blood glucose levels when compared with NC group, and HG200 group significantly $(P<0.05)$ ameliorated this decrease in the glucose level to near normal levels. No differences were found in lipid metabolites in all groups.

\section{Effects on sperm kinematics}

The effect of GINST on sperm kinematic values of heat-stressed rats was shown in Table 4. The sperm motility and progressive motion in the $\mathrm{HC}$ group were significantly decreased compared to those in the NC group $(P<0.05)$. However, the sperm motility in the GINST treatment group was significantly improved (HG100 and HG200; $P<0.05$ ). On the other hand, no differences were observed for average-path velocity (VAP), straight-line velocity (VSL), curvilinear velocity $(\mathrm{VCL})$, straightness (STR), linearity (LIN) and elongation, in both NC and HC group's indicating that heat stress did not influence these parameters.

\section{Effects on antioxidant enzyme expression}

To evaluate the spermatogenesis of rat testis, firstly, mRNA expressions of antioxidant-related enzymes were investigated with RT-PCR (Fig. 2A). GSTM5 is one of the glutathione S-transferases (GSTs) in testicular tissue, and PRX4 (peroxiredoxin) is expressed from the mitochondria of the testis. GSTM5 was significantly reduced in the $\mathrm{HC}$ group $(P<0.05)$. GSTM5 increased when GINST was administered in a high dose, but was not statistically significant. Although the NC and HC groups of GPX4 (glutathione peroxidase) and PRx4 did not show significant differences, the HG200 group of GPX4 had significantly increased values $(P<0.05)$. GAPDH was used as an internal control. The relative mRNA expression of GPX4, GSTM5 and PRx4 normalized to GAPDH was shown in Fig. 2B, $C$ and $D$ respectively. Western blot was conducted to

Table 2 Effect of GINST on organ weight in heat-stressed male rats.

\begin{tabular}{|c|c|c|c|c|}
\hline & \multicolumn{4}{|c|}{ Group } \\
\hline & $\mathrm{NC}$ & $\mathrm{HC}$ & HG100 & HG200 \\
\hline \multicolumn{5}{|l|}{ Organ weight (g) } \\
\hline Liver & $14.28 \pm 1.97$ & $13.73 \pm 2.11$ & $13.89 \pm 1.46$ & $14.73 \pm 1.89$ \\
\hline Spleen & $0.75 \pm 0.13$ & $0.78 \pm 0.07$ & $0.80 \pm 0.11$ & $0.79 \pm 0.08$ \\
\hline Kidney & $3.25 \pm 0.12$ & $3.10 \pm 0.10^{\sharp}$ & $3.07 \pm 0.12$ & $3.22 \pm 0.09 *$ \\
\hline Testis & $3.41 \pm 0.12$ & $3.36 \pm 0.03$ & $3.49 \pm 0.11 *$ & $3.52 \pm 0.09 *$ \\
\hline Heart & $1.69 \pm 0.20$ & $1.70 \pm 0.19$ & $1.73 \pm 0.14$ & $1.78 \pm 0.10$ \\
\hline Epididymis & $0.70 \pm 0.04$ & $0.66 \pm 0.01^{\#}$ & $0.68 \pm 0.01 *$ & $0.68 \pm 0.02 *$ \\
\hline Adrenal gland & $0.08 \pm 0.01$ & $0.08 \pm 0.01$ & $0.08 \pm 0.01$ & $0.08 \pm 0.01$ \\
\hline
\end{tabular}

Data are expressed as the mean \pm S.E.M. $(n=10)$. Statistical analysis was performed by ANOVA followed by Duncan's $t$-test using the SAS ver. 9.1 (SAS Inc., Cary, NC, USA).

${ }^{\sharp} P<0.05$ compared with the NC group and $* P<0.05$ compared with the HC group.

HC, heat-stressed control; HG100, heat-stressed + GINST $100 \mathrm{mg} / \mathrm{kg}$ b.w./day; HG200, heat-stressed + GINST 200 mg/kg b.w./day;

NC, normal control. 
Table 3 Effect of GINST on blood chemistry levels in heat-stressed male rats.

\begin{tabular}{|c|c|c|c|c|}
\hline \multirow[b]{2}{*}{ Blood Chemistry } & \multicolumn{4}{|c|}{ Group } \\
\hline & NC & $\mathrm{HC}$ & HG100 & HG200 \\
\hline GOT & $77.3 \pm 14.6$ & $105.5 \pm 23.5^{\#}$ & $96.3 \pm 35.8$ & $78.4 \pm 10.2^{*}$ \\
\hline$\gamma$-GPT & $26.5 \pm 5.8$ & $22.5 \pm 2.6$ & $23.0 \pm 3.9$ & $21.7 \pm 2.4^{\mathrm{b}}$ \\
\hline ALB (g/dL) & $2.7 \pm 0.1$ & $2.7 \pm 0.2$ & $2.7 \pm 0.1$ & $2.8 \pm 0.2$ \\
\hline $\mathrm{T}-\mathrm{CHO}$ & $89.3 \pm 20.5$ & $66.3 \pm 8.2$ & $74.1 \pm 10.1$ & $66.4 \pm 8.8$ \\
\hline $\mathrm{TG}(\mathrm{mg} / \mathrm{dL})$ & $70.5 \pm 29.7$ & $39.8 \pm 9.9$ & $43.9 \pm 20.1$ & $33.5 \pm 15.5$ \\
\hline LDL-C (mg/dL) & $6.0 \pm 2.2$ & $4.5 \pm 1.2$ & $3.8 \pm 1.8$ & $5.2 \pm 2.5$ \\
\hline GLU (mg/dL) & $161.5 \pm 10.5$ & $140.9 \pm 15.5^{\#}$ & $134.6 \pm 16.1$ & $164.8 \pm 27.4^{*}$ \\
\hline BUN (mg/dL) & $17.2 \pm 3.5$ & $17.8 \pm 4.8$ & $19.0 \pm 3.4$ & $25.8 \pm 5.0$ \\
\hline CRE (mg/dL) & $0.69 \pm 0.06$ & $0.72 \pm 0.07^{\#}$ & $0.69 \pm 0.08$ & $0.70 \pm 0.06$ \\
\hline
\end{tabular}

Data are expressed as the mean \pm S.E.M. $(n=10)$. Statistical analysis was performed by ANOVA followed by Duncan's $t$-test using the SAS ver. 9.1 (SAS Inc., Cary, NC, USA).

${ }^{\sharp} P<0.05$ compared with the $\mathrm{NC}$ group and ${ }^{*} P<0.05$ compared with the HC group.

ALB, albumin concentration; BUN, blood urea nitrogen; $\mathrm{CHO}$, total cholesterol concentration; $\mathrm{CRE}$, creatinine; GLU, glucose concentration; GOT, glutamic oxaloacetic transaminase activity; GPT, glutamic pyruvic transaminase activity; HC, heat-stressed control; HG100, heatstressed + GINST 100 mg/kg b.w./day; HG200, heat-stressed + GINST 200 mg/kg b.w./day; LDL, low-density lipoprotein; NC, normal control; TG, triglyceride concentration.

evaluate the protein expressions. Actin was used as an internal control. Figure $3 \mathrm{~A}$ shows antioxidant-related enzyme expressions and reveals similar results as the RT-PCR. GPX4 and GSTM5 were reduced by heat stress significantly $(P<0.05)$; however, GINST recovered the altered expressions (Fig. 3B, C and D). Heat stress did not influence the protein PRx4 levels significantly when compared with NC group.

\section{Effects on spermatogenesis-related molecule expression levels}

The effect of GINST on spermatogenesis-related molecules such as CREB1, nectin and INHA, was also evaluated at mRNA and protein levels. The mRNA expression levels of CREB1 and INHA, which act in the sex hormone pathway of spermatogenesis, were significantly $(P<0.05)$ downregulated in the $\mathrm{HC}$ group (Fig. 4). However, GINST significantly $(P<0.05)$ increased the expression level of INHA, which was downregulated by heat stress (Fig. 4B). GINST also significantly $(P<0.05)$ recovered the mRNA expressions of CREB1 in the HG100 and HG200 groups (Fig. 4C). Although nectin-2 expression was not influenced with heat stress when compared with NC group, HG200 group showed increased values compared to that of HC group $(P<0.05$; Fig. 4D). In western blot analysis, INHA was significantly downregulated in the $\mathrm{HC}$ group than that in NC $(P<0.05$; Fig. 5$)$. Nectin-2 and CREB1 were not influenced with heat stress compared to NC group. However, GINST-treated HG200 group showed increased CREB1 and INHA levels compared to $\mathrm{HC}$ group, and HG200 demonstrated significantly increased expression levels of the molecule $(P<0.05)$.

\section{Effects on sex hormone receptor expression}

As shown in Fig. 6, intermittent sub-chronic heat stress significantly suppressed the mRNA expression levels of the luteinizing hormone receptor (LHR, $P<0.05)$, follicle-stimulating hormone receptor (FSHR, $P<0.05$ ) and androgen receptor (AR, $P<0.05)$. However, GINST significantly $(P<0.05)$ alleviated the decrease in mRNA expression levels of the receptors in the heat-stressed rats (Fig. 6C and D). From the Western blot analysis (Fig. 7), sex hormone receptor expressions were all significantly $(\mathrm{LHR}, \mathrm{AR}$ and FSHR: $P<0.05)$ reduced by heat stress (Fig. 7C and D) and GINST attenuated the changes $(P<0.05)$.

Table 4 Effect of GINST on sperm kinematic values in heat-stressed male rats.

\begin{tabular}{lllllllll}
\hline Group & \multicolumn{1}{c}{ Motile $(\%)$} & Progressive $(\%)$ & VAP $(\mathrm{mm} / \mathrm{s})$ & VSL $(\mathrm{mm} / \mathrm{s})$ & \multicolumn{1}{c}{ VCL $(\mathrm{mm} / \mathrm{s})$} & \multicolumn{1}{c}{ STR $(\%)$} & LIN $(\%)$ & Elongation $(\%)$ \\
\hline NC & $91.67 \pm 6.29$ & $31.93 \pm 13.81$ & $32.87 \pm 6.39$ & $23.08 \pm 3.74$ & $76.00 \pm 14.41$ & $69.47 \pm 5.41$ & $39.33 \pm 5.61$ & $95.47 \pm 3.62$ \\
HC & $58.33 \pm 20.68^{\#}$ & $18.89 \pm 8.27^{\#}$ & $30.11 \pm 6.43$ & $21.78 \pm 8.78$ & $74.38 \pm 12.01$ & $73.33 \pm 7.48$ & $40.89 \pm 5.16$ & $97.89 \pm 2.52$ \\
HG100 & $90.40 \pm 9.73^{*}$ & $35.90 \pm 9.40^{*}$ & $35.04 \pm 5.21^{*}$ & $24.64 \pm 3.90$ & $80.50 \pm 7.93$ & $69.70 \pm 2.71$ & $38.90 \pm 3.03$ & $92.70 \pm 3.53 *$ \\
HG200 & $81.14 \pm 15.94^{*}$ & $30.29 \pm 16.02$ & $34.94 \pm 8.19$ & $23.94 \pm 7.17$ & $81.54 \pm 16.81$ & $68.86 \pm 5.98$ & $39.43 \pm 7.55$ & $96.00 \pm 4.36$ \\
\hline
\end{tabular}

Data are expressed as the mean \pm S.E.M. $(n=10)$. Statistical analysis was performed by ANOVA followed by Duncan's $t$-test using the SAS ver. 9.1 (SAS Inc., Cary, NC, USA).

${ }^{\sharp} P<0.05$ compared with the NC group and $* P<0.05$ compared with the HC group.

HC, heat-stressed control; HG100, heat-stressed + GINST $100 \mathrm{mg} / \mathrm{kg}$ b.w./day; HG200, heat-stressed + GINST 200 mg/kg b.w./day; LIN, linearity =VSL/NCL $\times 100 ; \mathrm{NC}$, normal control; STR, straightness =VSL/VAP $\times 100$; VAP, average path velocity; VCL, curvilinear velocity; VSL, straight-line velocity. 
A

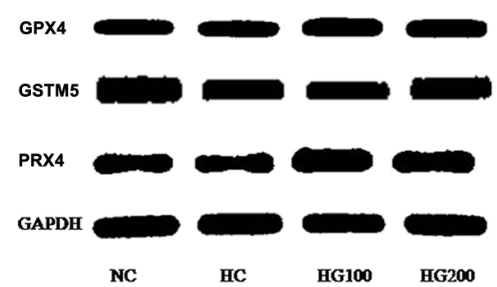

C

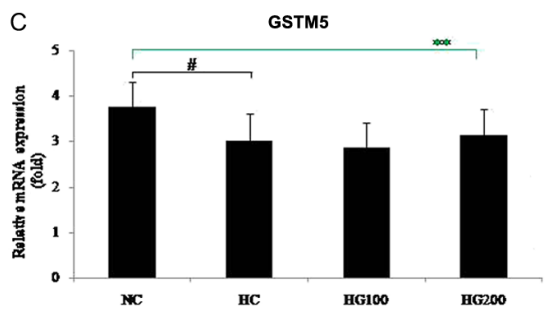

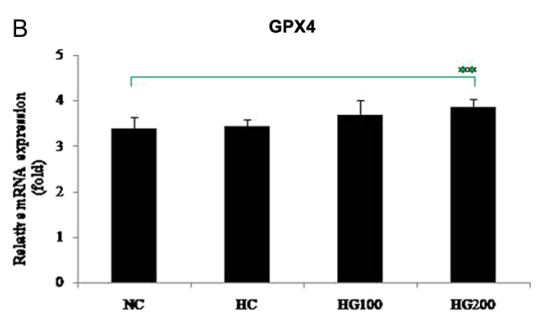

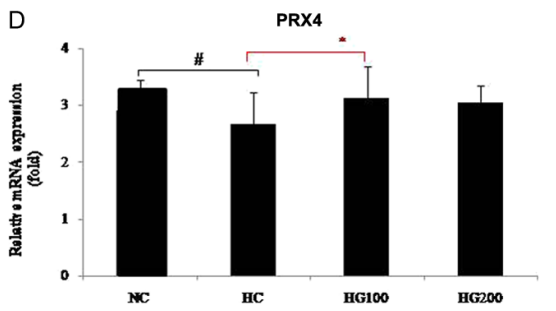

Figure 2 Effect of GINST on mRNA (A) expression of antioxidant enzymes in rat testes. (A) The mRNA expression of GPX4, GSTM5 and PRx4in rat testicular tissue. The internal control used was GAPDH. Relative expression level (fold) of GPX4 (B), GSTM5 (C) and $\mathrm{PRx} 4(\mathrm{D})$ in three independent experiments normalized to that of GAPDH was shown. Data are expressed as mean \pm S.E.M. $(n=10)$. Statistical analysis was carried out by Student's $t$-test and one-way ANOVA using GraphPad Prism, version 4.0. ${ }^{\sharp} P<0.05$ compared with the NC group and $* P<0.05$ compared with HC vs HG100 group (red color), NC vs HG100 and HG 200 groups (* and ${ }^{* *}$, respectively green color). $\mathrm{NC}$, normal control; $\mathrm{HC}$, heat-stressed control; HG100, heat-stressed + GINST $100 \mathrm{mg} / \mathrm{kg}$ b.w./ day; HG200, heat-stressed + GINST 200 mg/kg b.w./day; GPX4, glutathione peroxidase 4; GSTM5, glutathione S-transferase mu 5; $\mathrm{PRx} 4$, peroxiredoxin 4; GAPDH, glyceraldehyde 3-phosphate dehydrogenase.

\section{Content of ginsenosides in GINST}

The HPLC fingerprint for ginsenosides in pectinasetreated ginseng extracts is shown in Fig. 8. The ginsenoside content in the extract accounted for $\operatorname{Rg} 1$ $(43.17 \mathrm{mg} / \mathrm{g}), \operatorname{Rf}(65.41 \mathrm{mg} / \mathrm{g}), \mathrm{Rh} 1(30.12 \mathrm{mg} / \mathrm{g}), \mathrm{Rg} 2 \mathrm{~S}$ $(9.87 \mathrm{mg} / \mathrm{g}), \operatorname{Rg} 2 R(9.34 \mathrm{mg} / \mathrm{g}), \mathrm{Rb} 1(17.49 \mathrm{mg} / \mathrm{g}), \mathrm{Rb} 2$ $(77.85 \mathrm{mg} / \mathrm{g}), \quad \mathrm{Rd}(101.12 \mathrm{mg} / \mathrm{g}), \operatorname{Rg} 3 \quad S(22.41 \mathrm{mg} / \mathrm{g})$, Rg3 $R(26.57 \mathrm{mg} / \mathrm{g})$, compound $\mathrm{K}(274.15 \mathrm{mg} / \mathrm{g})$, Rh2 $S$ $(32.16 \mathrm{mg} / \mathrm{g})$ and $\mathrm{Rh} 2 R(51.11 \mathrm{mg} / \mathrm{g})$.

\section{Discussion}

Heat is one of the various environmental factors that adversely affect spermatogenesis. Spermatogenesis occurs optimally at temperatures slightly lower $\left(2-4^{\circ} \mathrm{C}\right)$ than the core body temperature (Ivell 2007, Durairajanayagam et al. 2015). Previous studies suggest that heat can induce increased apoptosis of germ cells and DNA damage (Kim et al. 2013, Durairajanayagam et al. 2015). The effect of heat stress on sperm profiles and
A
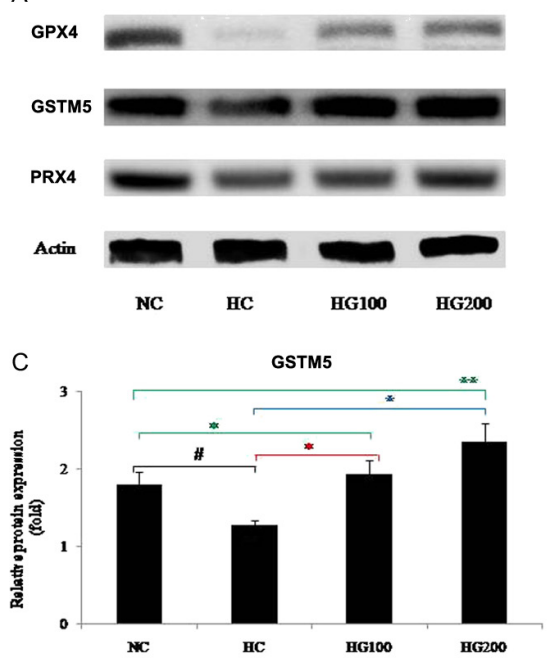
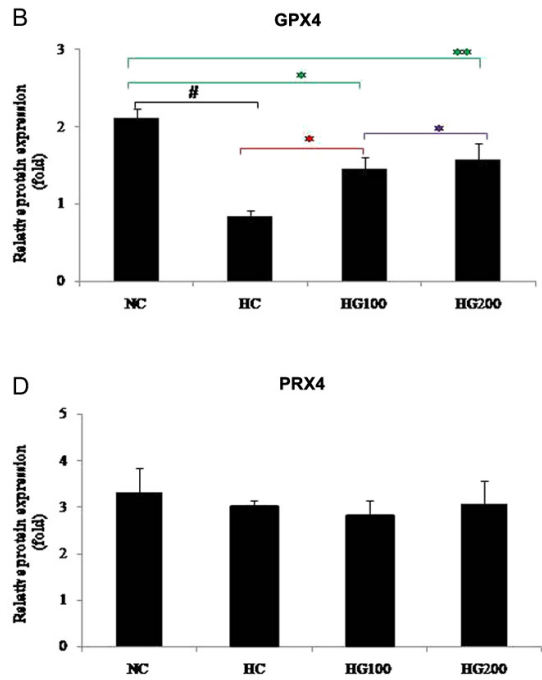

Figure 3 Effect of GINST on protein expression of antioxidant enzymes in rat testes. (A) Protein expression of GPX4, GSTM5 and PRx4 in testicular tissue was analyzed using western blot analysis. Internal control used was $\beta$-actin. Data are expressed as the ratio of the analyzed protein to internal control proteins. (B) Relative expression levels (fold) of GPX4, (C) GSTM5 and (D) PRx4 in three independent experiments normalized to $\beta$-actin. Data are expressed as mean \pm S.E.M. $(n=10)$. Statistical analysis was carried out by Student's $t$-test and one-way ANOVA using GraphPad Prism version 4.0. ${ }^{\sharp} P<0.05$ compared with the NC group and $* P<0.05$ compared with $\mathrm{HC}$ vs HG100 group (red color), HC vs HG200 group (blue color), NC vs HG100 and HG 200 groups (* and $*^{*}$, respectively; green color); and HG100 vs HG200 groups (purple color). $\mathrm{NC}$, normal control; HC, heat-stressed control; HG100, heat-stressed + GINST 100 mg/kg b.w./day; HG200, heat-stressed + GINST $200 \mathrm{mg} / \mathrm{kg}$ b.w./day; GPX4, glutathione peroxidase 4; GSTM5, glutathione S-transferase mu 5; PRx4, peroxiredoxin 4. 
A
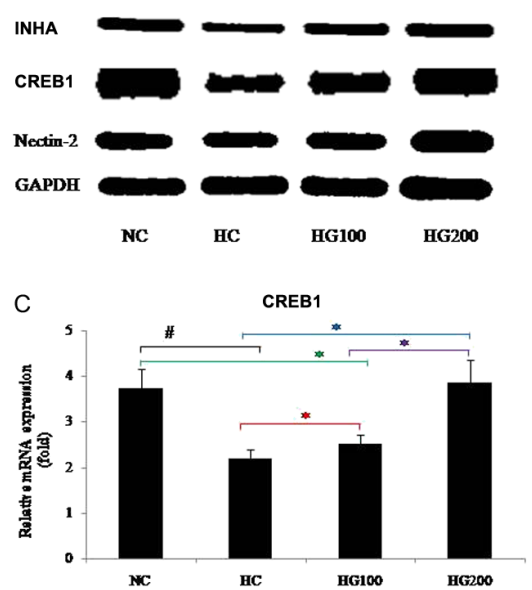
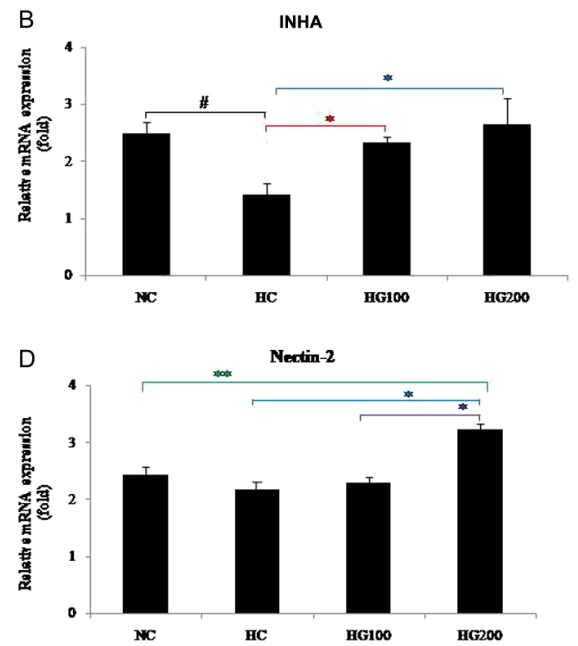

Figure 4 Effect of GINST on mRNA expression levels of spermatogenesis-related molecules in rat testes. (A) The mRNA expression of INHA, CREB1 and nectin-2 in rat testicular tissue. The internal control used was GAPDH. Relative expression level (fold) of INHA (B), CREB1 (C) and nectin-2 (D) in three independent experiments normalized to that of GAPDH was shown. Data are expressed as mean \pm S.E.M. $(n=10)$. Statistical analysis was carried out by Student's $t$-test and one-way ANOVA using GraphPad Prism, version 4.0. ${ }^{\sharp} P<0.05$ compared with the NC group and $* P<0.05$ compared with HC vs HG100 group (red color), HC vs HG200 group (blue color), NC vs HG100 and HG 200 groups (* and **, respectively; green color); and HG100 vs HG200 groups (purple color). NC, normal control; HC, heat-stressed control; HG100, heat-stressed + GINST 100 mg/kg b.w./day; HG200, heat-stressed + GINST $200 \mathrm{mg} / \mathrm{kg}$ b.w./day; CREB1, cyclic adenosine monophosphate (CAMP) responsive element binding protein; GAPDH, glyceraldehyde 3-phosphate dehydrogenase. oxidative status of semen and epididymal sperm were also studied by Hamilton and coworkers (Hamilton et al. 2016). They describe the testicular heat stress induced oxidative stress, which led to reversible alterations in sperm characters. Referring to these previous studies, endogenous or exogenous heat sources can aggravate infertility. For example, endogenous factors include obesity, fever, varicocele and cryptorchidism. Exogenous factors, such as saunas or hot tub baths for longer periods and frequent usage, impaired spermatogenesis (Rao et al. 2015). Even trivial daily acts such as frequent laptop computer usage for a long time have also caused significant scrotal hyperthermia resulting in a possible negative effect on spermatogenesis (Sheynkin et al. 2005). These endogenous or transient exogenous factors may be avoided or removed by surgery. However, if the factors remain as chronic exposures, such as living in high-temperature regions or working in such environments, it will be difficult to avoid these factors.

The present study demonstrated the beneficial role of GINST in spermatogenesis in a heat-stressed rat model. Reports demonstrated that GINST exhibited
A

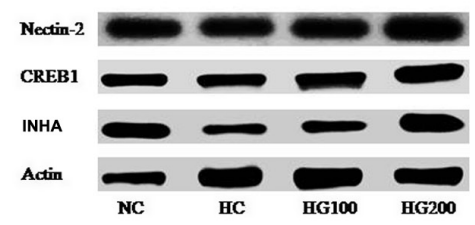

C

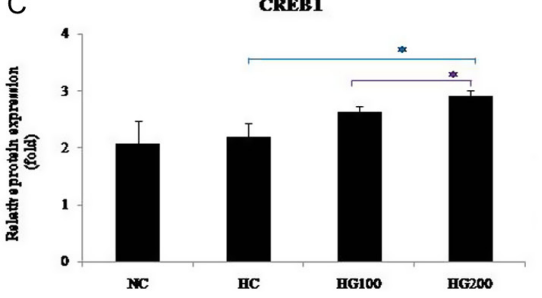

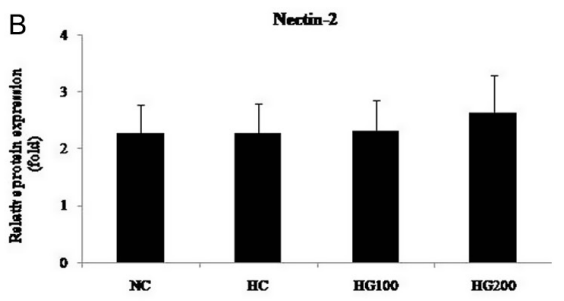

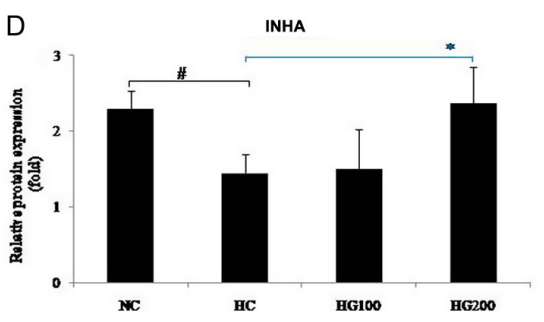

Figure 5 Effect of GINST on protein expression levels of spermatogenesis-related molecules in rat testes. (A) Protein expression of nectin-2, CREB1 and INHA in testicular tissue was analyzed using Western blot analysis. Internal control used was actin. Data are expressed as the ratio of the analyzed protein to internal control proteins. (B) Relative expression levels (fold) of nectin-2, (C) CREB1 and (D) INHA in three independent experiments normalized to actin. Data are expressed as mean \pm S.E.M. $(n=10)$. Statistical analysis was carried out by Student's $t$-test and one-way ANOVA using GraphPad Prism, version 4.0. ${ }^{*} P<0.05$ compared with the NC group and $* P<0.05$ compared with HC vs HG200 group (blue color), NC vs HG100 and HG 200 groups (* and ${ }^{* *}$, respectively; green color); HG100 vs HG200 groups (purple color). NC, normal control; HC, heat-stressed control; HG100, heat-stressed + GINST $100 \mathrm{mg} / \mathrm{kg}$ b.w./day; HG200, heat-stressed + GINST $200 \mathrm{mg} / \mathrm{kg}$ b.w./ day; CREB1, cyclic adenosine monophosphate (CAMP) responsive element binding protein. 
A
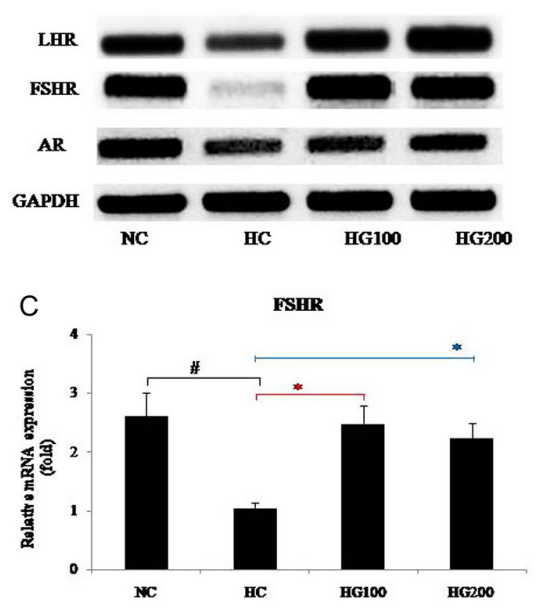

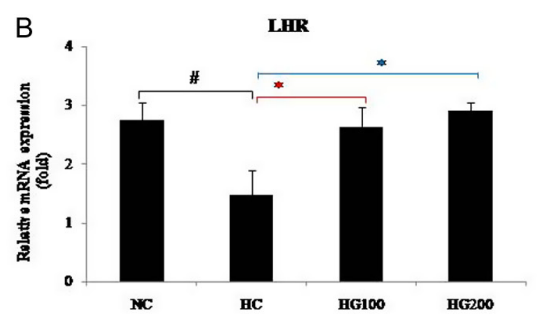

D

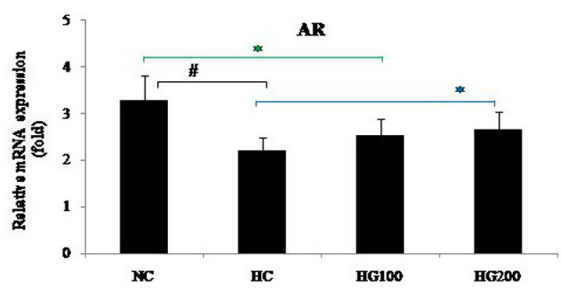

Figure 6 Effect of GINST on mRNA expression of sex hormone receptors in rat testes. (A) The mRNA expression of LHR, FSHR and AR in rat testicular tissue. The internal control used was GAPDH. Relative expression level (fold) of LHR (B), FSHR (C) and AR (D) in three independent experiments normalized to that of GAPDH was shown. Data are expressed as mean \pm S.E.M. $(n=10)$. Statistical analysis was carried out by Student's $t$-test and one-way ANOVA using GraphPad Prism version 4.0. ${ }^{\sharp} P<0.05$ compared with the NC group and $* P<0.05$ compared with HC vs HG100 group (red color), HC vs HG200 group (blue color), NC vs HG100 and HG 200 groups (* and **, respectively; green color). NC, normal control; $\mathrm{HC}$, heat-stressed control; HG100, heatstressed + GINST 100 mg/kg b.w./day; HG200, heat-stressed + GINST 200 mg/kg b.w./day; AR, androgen receptor; LHR, luteinizing hormone receptor; FSHR, follicle-stimulating hormone receptor; GAPDH, glyceraldehyde 3-phosphate dehydrogenase. various beneficial pharmacological effects including antioxidant, antidiabetic and antitumor activities (Chen et al. 2008, Yuan et al. 2011, Yu et al. 2013). Compared to Panax ginseng, GINST contains large amounts of $\mathrm{CK}$, which is a biotransformation product of $\mathrm{Rb} 1, \mathrm{Rb} 2$ and Rc, as well as other ginsenosides, such as Rg3, Rg5, Rk1, Rh1, F2 and Rg2, which are helpful for these activities (Chen et al. 2008). Previous studies have shown ginseng acting as a defense against environmental heat stress in various ways. One study suggested ginseng root saponins inhibited the increase of serum corticosterone and decrease of brain 5-HT and NE in heat-stressed mice (Yuan et al. 1989). Another study described that red ginseng repressed the heat stress-mediated hepatic cell death by inhibiting $\mathrm{Bcl}-2$ expression in rats (Kim et al. 2015).

The present study also revealed that heat-stressed rats had decreased weights of various organs, especially the kidney and epididymis, but GINST inhibited such weight reductions. Additionally, GINST alleviated the heat-induced alteration in blood chemistry panels, especially GOT and glucose levels, in rats. This indicates that GINST may protect the pancreas, liver and kidney, in addition to the epididymis, from heat-induced cell damage.

The present study was the first to prove that GINST inhibited heat-stress alterations in rats that can result in male subfertility. First, the reduced epididymis weight
A
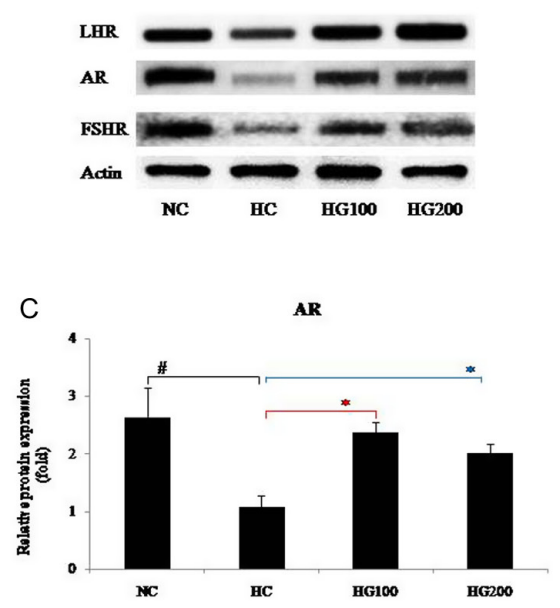
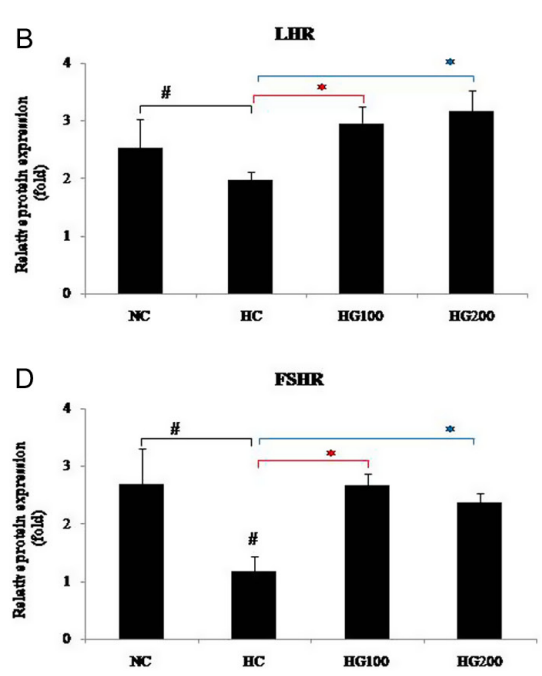

Figure 7 Effect of GINST protein expression of sex hormone receptors in rat testes. (A) Protein expression of LHR, AR and FSHRin testicular tissue was analyzed using Western blot analysis. Internal control used was actin. Data are expressed as the ratio of the analyzed protein to internal control proteins. (B) Relative expression levels (fold) of LHR, (C) AR and (D) FSHR in three independent experiments normalized to actin. Data are expressed as mean \pm S.E.M. $(n=10)$. Statistical analysis was carried out by Student's $t$-test and one-way ANOVA using GraphPad Prism version 4.0. ${ }^{\sharp} P<0.05$ compared with the NC group and $* P<0.05$ compared with $\mathrm{HC}$ vs HG100 group (red color), HC vs HG200 group (blue color). NC, normal control; HC, heat-stressed control; HG100, heatstressed + GINST 100 mg/kg b.w./day; HG200, heat-stressed + GINST 200 mg/kg b.w./day; AR, androgen receptor; LHR, luteinizing hormone receptor; FSHR, follicle-stimulating hormone receptor. 


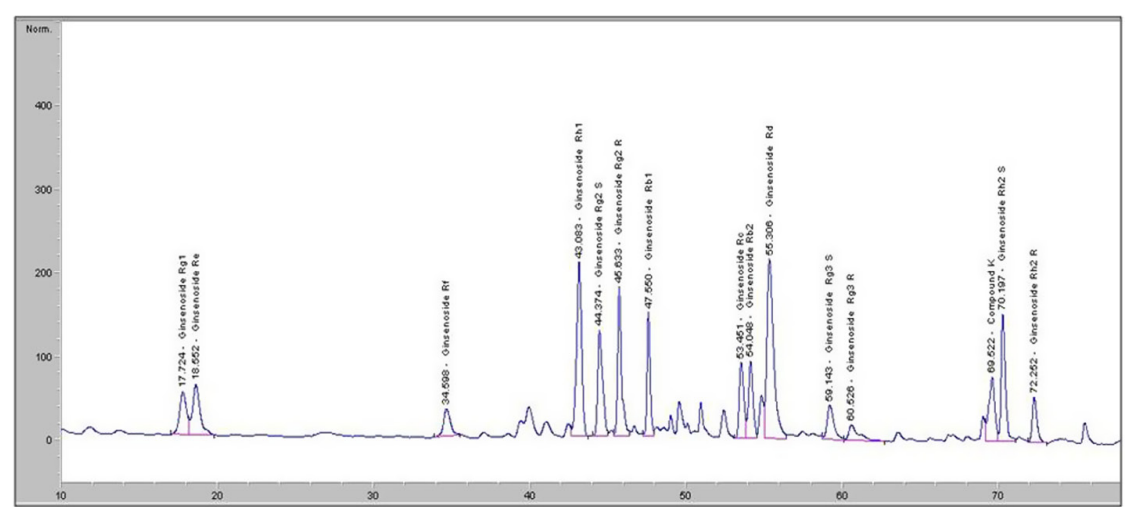

Figure 8 Ginsenoside HPLC profiles in pectinase-treated ginseng extract (GINST). Instrument; Agilent HPLC system, Column; HS C18 $(4.6 \times 250 \mathrm{~mm}, 5 \mu \mathrm{m}$; SUPELCO, St Louis, Missouri, USA), Mobile-phase; water (solvent A) and acetonitrile (solvent B): $0-10 \mathrm{~min}(20 \%$ B), $40 \mathrm{~min}(32 \% \mathrm{~B}), 48 \mathrm{~min}(42 \% \mathrm{~B}), 60 \mathrm{~min}$ $(45 \% \mathrm{~B}), 78 \mathrm{~min}(75 \% \mathrm{~B}), 80 \mathrm{~min}(100 \% \mathrm{~B})$, Flow rate; $1.6 \mathrm{~mL} / \mathrm{min}$. in heat-stress group was significantly increased when GINST was administered. This result shows that GINST possibly inhibits the reduction of sperm concentration and number by protecting the epididymis damage. Second, the heat-stress model showed decreased sperm motility, but GINST-administered heat-stress models recovered the motility. This is in line with previous clinical trials that revealed sperm concentrations, motility, morphology and viability were significantly improved in KRG-treated male infertility patients (Park et al. 2016).

Third, several antioxidant-related enzymes were recovered using GINST. Oxidative stress triggers various diseases, and studies have shown that increased oxidative stress was found in cryptorchidism or varicocele patients with higher testicular temperatures (Peltola et al. 1995, Tawadrous et al. 2013). Human spermatozoa are very susceptible to oxidative stress, which can be detrimental to the sperm plasma membrane and DNA fragmentation of both nuclear and mitochondrial genomes (Aitken \& Baker 2006, Tremellen 2008). Having understood these evidences, it is highly notable that GINST reduces that oxidative stress and also provides protection from it to allow normal spermatogenesis in the testis.

Fourth, the spermatogenesis-related protein, INHA, was protected from heat-induced damage. These proteins represent the testicular spermatogenesis function. CREB1 is an important molecular regulator of testicular development and spermatogenesis as it is expressed during mitotic phase of spermatocytogenesis and the differentiation phase of spermiogenesis (Don \& Stelzer 2002, Kim et al. 2009). Nectin-2 is an important adhesion molecule in the Sertoli germ cell junction and helps the development of the matured spermatozoa in the seminiferous epithelium (Morrison \& Racaniello 1992). INHA plays an important role in development of the round spermatid during spermatogenesis (Cai et al. 2011). The current findings of this study explain that INHA and CREB1 mRNA expression levels were harmfully affected by heat stress. However, GINST significantly reversed the heat-induced mRNA expression alterations, and protein expressions were also improved. It can be speculated that GINST might regulate certain key transcriptions and restore signal transduction important in spermatogenesis.

Lastly, the sex hormone receptor expressions were downregulated by heat stress, but GINST was able to halt the process. Many sex hormones such as FSH, $\mathrm{LH}$ and androgens are vital in the process of germ cell apoptosis and survival (Xu et al. 2016). Previous studies demonstrated that germ cells died after hormone deprivation by inducing intrinsic apoptotic signals (Jia et al. 2007, Wang et al. 2007). In agreement with these findings, heat stress lowered the levels of sex hormone receptors, and consequently, increased germ cell apoptosis. However, as described in our previous studies, GINST treatment attenuated the declining levels of sex hormones (Won et al. 2014, Kopalli et al. 2016) and the sex hormone receptors. This demonstrates that GINST may effectively regulate the sex hormone level and biomarker molecules important for spermatogenesis and function.

In conclusion, this study has provided considerable data on the positive effect of GINST on male infertility factors. GINST effectively protected antioxidantrelated enzymes, spermatogenesis-related proteins, sex hormone receptors, and consequently, the sperm quality in heat-stressed rats. Clinical trials are in progress to confirm the GINST effect in human male infertility patients.

\section{Declaration of interest}

The authors declare that there is no conflict of interest that could be perceived as prejudicing the impartiality of the research reported.

\section{Funding}

This study was supported by Korea Institute of Planning \& Evaluation for Technology in Food, Agriculture, Forestry \& Fisheries, Korea (Grant no: 113040-3). 


\section{References}

Aitken RJ \& Baker MA 2006 Oxidative stress, sperm survival and fertility control. Molecular and Cellular Endocrinology 250 66-69. (doi:10.1016/j.mce.2005.12.026)

Bardaweel SK 2014 Alternative and antioxidant therapies used by a sample of infertile males in Jordan: a cross-sectional survey. BMC Complementary and Alternative Medicine 14 244. (doi:10.1186/14726882-14-244)

Berek JS 2012 Berek and Novak's Gynecology. edn 15, pp 1970. Philadelphia: Lippincott Williams and Wilkins.

Cai K, Hua G, Ahmad S, Liang A, Han L, Wu C, Yang F \& Yang L 2011 Action mechanism of inhibin alpha-subunit on the development of Sertoli cells and first wave of spermatogenesis in mice. PLOS ONE 6 e25585. (doi:10.1371/journal.pone.0025585)

Chen GT, Yang M, Song Y, Lu ZQ, Zhang JQ, Huang HL, Wu LJ \& Guo DA 2008 Microbial transformation of ginsenoside Rb(1) by Acremonium strictum. Applied Microbiology and Biotechnology 77 1345-1350. (doi:10.1007/s00253-007-1258-4)

Don J \& Stelzer G 2002 The expanding family of CREB/CREM transcription factors that are involved with spermatogenesis. Molecular and Cellular Endocrinology 187 115-124. (doi:10.1016/S0303-7207(01)00696-7)

Du GJ, Dai Q, Williams S, Wang CZ \& Yuan CS 2011 Synthesis of protopanaxadiol derivatives and evaluation of their anticancer activities. Anticancer Drugs 22 35-45. (doi:10.1097/ CAD.0b013e32833fde29)

Durairajanayagam D, Agarwal A \& Ong C 2015 Causes, effects and molecular mechanisms of testicular heat stress. Reproductive BioMedicine Online 30 14-27. (doi:10.1016/j.rbmo.2014.09.018)

Eisenberg ML, Li S, Cullen MR \& Baker LC 2016 Increased risk of incident chronic medical conditions in infertile men: analysis of United States claims data. Fertility and Sterility 105 629-636. (doi:10.1016/j. fertnstert.2015.11.011)

Eslamian G, Amirjannati N, Rashidkhani B, Sadeghi MR \& Hekmatdoost A 2016 Nutrient patterns and asthenozoospermia: a case-control study. Andrologia. 49 1-6. (doi:10.1111/and.12624)

Gabrielsen JS \& Tanrikut C 2016 Chronic exposures and male fertility: the impacts of environment, diet, and drug use on spermatogenesis. Andrology 4 648-661 (doi:10.1111/andr.12198)

Ha DC \& Ryu GH 2005 Chemical components of red, white and extruded root ginseng. Journal of the Korean Society of Food Science and Nutrition 34 247-254. (doi:10.3746/jkfn.2005.34.2.247)

Hamilton TR, Mendes CM, de Castro LS, de Assis PM, Siqueira AF, Delgado Jde C, Goissis MD, Muino-Blanco T, Cebrian-Perez JA, Nichi M et al. 2016 Evaluation of lasting effects of heat stress on sperm profile and oxidative status of ram semen and epididymal sperm. Oxidative Medicine and Cellular Longevity 20161687657. (doi:10.1155/2016/1687657)

Huo R, He Y, Zhao C, Guo XJ, Lin M \& Sha JH 2008 Identification of human spermatogenesis-related proteins by comparative proteomic analysis: a preliminary study. Fertility and Sterility 90 1109-1118.

Hwang SY, Kim WJ, Wee J, Choi JS \& Kim SK 2004 Panax ginseng improves survival and sperm quality in guinea pigs exposed to 2,3,7,8-tetrachlorodibenzo-p-dioxin. BU International 94 663-668. (doi:10.1111/j.1464-410X.2004.05019.x)

Ivell R 2007 Lifestyle impact and the biology of the human scrotum. Reproductive Biology and Endocrinology 5 15. (doi:10.1186/14777827-5-15)

Jia Y, Hikim AP, Lue YH, Swerdloff RS, Vera Y, Zhang XS, Hu ZY, Li YC, Liu YX \& Wang C 2007 Signaling pathways for germ cell death in adult cynomolgus monkeys (Macaca fascicularis) induced by mild testicular hyperthermia and exogenous testosterone treatment. Biology of Reproduction 77 83-92. (doi:10.1095/biolreprod.106.058594)

Kim CS, Jang DS \& Che SY 2006 Histological characteristics of korean red ginseng in steaming processes. Korean Journal of Medicinal Crop Science 14 36-40.

Kim JS, Song MS, Seo HS, Yang M, Kim SH, Kim JC, Kim H, Saito TR, Shin T \& Moon C 2009 Immunohistochemical analysis of cAMP response element-binding protein in mouse testis during postnatal development and spermatogenesis. Histochemistry and Cell Biology 131 501-507. (doi:10.1007/s00418-009-0554-8)
Kim B, Park K \& Rhee K 2013 Heat stress response of male germ cells. Cellular and Molecular Life Sciences 70 2623-2636. (doi:10.1007/ s00018-012-1165-4)

Kim KJ, Yoon KY, Hong HD \& Lee BY 2015 Role of the red ginseng in defense against the environmental heat stress in Sprague Dawley rats. Molecules 20 20240-20253. (doi:10.3390/molecules201119692)

Kopalli SR, Hwang SY, Won YJ, Kim SW, Cha KM, Han CK, Hong JY \& Kim SK 2015 Korean red ginseng extract rejuvenates testicular ineffectiveness and sperm maturation process in aged rats by regulating redox proteins and oxidative defense mechanisms. Experimental Gerontology 69 94-102. (doi:10.1016/j.exger.2015.05.004)

Kopalli SR, Cha KM, Jeong MS, Lee SH, Sung JH, Seo SK \& Kim SK 2016 Pectinase-treated Panax ginseng ameliorates hydrogen peroxideinduced oxidative stress in GC-2 sperm cells and modulates testicular gene expression in aged rats. Journal of Ginseng Research 40 185-195. (doi:10.1016/j.jgr.2015.08.005)

Lee Y-M, Yoon H, Park H-M, Song BC \& Yeum K-J 2016 Implications of red Panax ginseng in oxidative stress associated chronic diseases. Journal of Ginseng Research. Epub ahead of print. (doi:10.1016/j.jgr.2016.03.003)

Liu XX, Shen XF \& Liu FJ 2016 Screening targeted testisspecific genes for molecular assessment of aberrant sperm quality. Molecular Medicine Reports 14 1594-1600. (doi:10.3892/mmr.2016.5434)

Morrison ME \& Racaniello VR 1992 Molecular cloning and expression of a murine homolog of the human poliovirus receptor gene. Journal of Virology 66 2807-2813.

Park HJ, Choe S \& Park NC 2016 Effects of Korean red ginseng on semen parameters in male infertility patients: a randomized, placebo-controlled, double-blind clinical study. Chinese Journal of Integrative Medicine 22 490-495. (doi:10.1007/s11655-015-2139-9)

Peltola V, Huhtaniemi I \& Ahotupa M 1995 Abdominal position of the rat testis is associated with high level of lipid peroxidation. Biology of Reproduction 53 1146-1150. (doi:10.1095/biolreprod53.5.1146)

Ramesh T, Kim SW, Hwang SY, Sohn SH, Yoo SK \& Kim SK 2012 Panax ginseng reduces oxidative stress and restores antioxidant capacity in aged rats. Nutrition Research 32 718-726. (doi:10.1016/j. nutres.2012.08.005)

Rao M, Zhao XL, Yang J, Hu SF, Lei H, Xia W \& Zhu CH 2015 Effect of transient scrotal hyperthermia on sperm parameters, seminal plasma biochemical markers, and oxidative stress in men. Asian Journal of Andrology 17 668-675. (doi:10.4103/1008-682X.146967)

Rao M, Xia W, Yang J, Hu LX, Hu SF, Lei H, Wu YQ \& Zhu CH 2016 Transient scrotal hyperthermia affects human sperm DNA integrity, sperm apoptosis, and sperm protein expression. Andrology 4 1054-1063 (doi:10.1111/andr.12228)

Sheynkin Y, Jung M, Yoo P, Schulsinger D \& Komaroff E 2005 Increase in scrotal temperature in laptop computer users. Human Reproduction $\mathbf{2 0}$ 452-455. (doi:10.1093/humrep/deh616)

Tawadrous GA, Aziz AA \& Mostafa T 2013 Seminal soluble fas relationship with oxidative stress in infertile men with varicocele. Urology 82 820-823. (doi:10.1016/j.urology.2013.06.018)

Tremellen K 2008 Oxidative stress and male infertility - a clinical perspective. Human Reproduction Update 14 243-258. (doi:10.1093/ humupd/dmn004)

Vogler BK, Pittler MH \& Ernst E 1999 The efficacy of ginseng. A systematic review of randomised clinical trials. European Journal of Clinical Pharmacology 55 567-575. (doi:10.1007/s002280050674)

Wang C, Cui YG, Wang XH, Jia Y, Sinha Hikim A, Lue YH, Tong JS, Qian LX, Sha JH, Zhou ZM et al. 2007 Transient scrotal hyperthermia and levonorgestrel enhance testosterone-induced spermatogenesis suppression in men through increased germ cell apoptosis. Journal of Clinical Endocrinology and Metabolism 92 3292-3304. (doi:10.1210/ jc.2007-0367)

Won YJ, Kim BK, Shin YK, Jung SH, Yoo SK, Hwang SY, Sung JH \& Kim SK 2014 Pectinase-treated Panax ginseng extract (GINST) rescues testicular dysfunction in aged rats via redox-modulating proteins. Experimental Gerontology 53 57-66. (doi:10.1016/j. exger.2014.02.012)

Xu YR, Dong HS \& Yang WX 2016 Regulators in the apoptotic pathway during spermatogenesis: killers or guards? Gene $\mathbf{5 8 2}$ 97-111. (doi:10.1016/j.gene.2016.02.007) 
Yao DF \& Mills JN 2016 Male infertility: lifestyle factors and holistic, complementary, and alternative therapies. Asian Journal of Andrology 18 410-418. (doi:10.4103/1008-682X.175779)

Yayeh T, Jung KH, Jeong HY, Park JH, Song YB, Kwak YS, Kang HS, Cho JY, Oh JW, Kim SK et al. 2012 Korean red ginseng saponin fraction downregulates proinflammatory mediators in LPS stimulated RAW264.7 cells and protects mice against endotoxic shock. Journal of Ginseng Research 36 263-269. (doi:10.5142/jgr.2012.36.3.263)

Yuan WX, Wu XJ, Yang FX, Shang XH \& Zhang LL 1989 Effects of ginseng root saponins on brain monoamines and serum corticosterone in heatstressed mice. Zhongguo Yao Li Xue Bao 10 492-496.

Yuan HD, Quan HY, Jung MS, Kim SJ, Huang B, Kim do Y, Chung SH 2011 Anti-diabetic effect of pectinase-processed ginseng radix (GINST) in high fat fiet-fed ICR mice. Journal of Ginseng Research 35 308-314. (doi:10.5142/jgr.2011.35.3.308)

Yu RQ, Yuan JL, Ma LY, Qin QX \& Wu XY 2013 Probiotics improve obesityassociated dyslipidemia and insulin resistance in high-fat diet-fed rats. Zhongguo Dang Dai Er Ke Za Zhi 15 1123-1127.

Received 10 October 2016

First decision 10 November 2016

Revised manuscript received 13 February 2017

Accepted 3 March 2017 